\title{
Evaluation of the antimycobacterial activity of crude extracts and solvent fractions of selected Ethiopian medicinal plants
}

\author{
Wubayehu Kahaliw ${ }^{1 *}$, Abraham Aseffa ${ }^{2}$, Markos Abebe ${ }^{2}$, Mekonen Teferi' ${ }^{2}$ and Ephrem Engidawork ${ }^{3}$
}

\begin{abstract}
Background: Tuberculosis (TB) is a global health problem complicated by drug resistance and human immunodeficiency virus that has dramatically increased active TB. Several medicinal plants are used traditionally to treat TB in Ethiopia and investigating these plants is required as plants are an alternative source for development of new anti-TB drugs. The purpose of this study was to investigate antimycobacterial activity of crude extract of Carissa edulis, Otostegia integrifolia, Persea americana, Pterolobium stellatum and Vernonia amygdalina as well as fractions of the most active crude extract.

Methods: The effect of various doses of the crude extracts as well as solvent fractions on M. tuberculosis H37Rv and/or MDR-TB clinical isolate was determined using broth microdilution and microtiter resazurin assay methods. Minimum inhibitory concentration was determined by CFU count and resazurin color change observation.

Results: Chloroform and $80 \%$ methanol extracts of P. stellatum and O. integrifolia as well as $80 \%$ methanol and acetone extracts of $P$. americana had significant antimycobacterial activity $(p<0.001)$ against M. tuberculosis H37Rv. Chloroform extract of $V$. amygdalina and $C$. edulis didn't, however, show any significant activity compared to negative controls. $P$. stellatum chloroform extract was the most active on M. tuberculosis H37Rv (MIC $0.039 \mathrm{mg} / \mathrm{ml}$ ) and AOZ8W-4 (MDR-TB clinical isolate) ( $M I C=0.078 \mathrm{mg} / \mathrm{ml})$. Ethyl acetate fraction of $P$. stellatum chloroform extract was the most active fraction.

Conclusion: $P$. stellatum, $O$. integrifolia and P. americana were found to be endowed with antimycobacterial activity. However, P. stellatum appears to be the most promising plant based on criteria set by different studies. Ethyl acetate fraction of $P$. stellatum was found to be the most active and future studies should involve this fraction.
\end{abstract}

Keywords: Tuberculosis, Resazurin, Antimycobacterial activity, Solvent fractions, Crude extract, Medicinal plants

\section{Background}

Mycobacterium tuberculosis, an obligate aerobe belonging to the M. tuberculosis complex (also include M. bovis, $M$. africanum and $M$. microti), is the most important cause of TB in humans. In addition to $M$. tuberculosis complex, Mycobacterium avium complex (include $M$. avium, M. intracellularae, and M. kansasii) can also cause closely related mycobacterium diseases in AIDS patients and is difficult to distinguish as a group clinically [1].

In 1993, during the world TB day, WHO declared TB as a 'global emergency', which requires emergency action and

\footnotetext{
*Correspondence: kahaliw_w@yahoo.com

'Department of Pharmacology, School of Pharmacy, College of Medicine and Health Sciences, University of Gondar, P. O. Box: 196, Gondar, Ethiopia Full list of author information is available at the end of the article
}

launched several programs to combat the disease, including the search for newer remedies and/or anti-TB agents to complement currently used agents [2]. In the year 2014, TB killed 1.5 million people (1.1 million HIVnegative and 0.4 million HIV-positive) and 9.6 million new cases of active tuberculosis globally caused by TB [3].

Mycobacteria are slow growing organisms that require administration of a combination of drugs for extended periods to achieve effective therapy and to prevent the emergence of resistance. The risk of adverse reactions therefore must be a major consideration in drug selection. Apart from significant toxicity, lengthy therapy also creates poor patient compliance. Non-compliance is a frequent cause of a deadly multidrug resistant $\mathrm{TB}$ (MDR-TB) and extensively drug resistant TB (XDR-TB). Drug toxicity coupled with the problem of mycobacterial 
persistence highlights the need to develop novel TB drugs that are active against drug resistant bacteria and kill persistent bacteria as well as shorten the length of TB treatment [4].

Natural products, either as pure compounds or as standardized plant extracts, provide unlimited opportunities for new drug leads because of the unmatched availability of chemical diversity [5]. Scientific interest in medicinal plant has grown in recent times because natural products are evolutionary shaped drugs or drug-like molecules. Nature's biosynthetic machinery produces innumerate natural products with distinct biological properties that make them valuable as inhibitors or promoters of biological action [4, 6]. Moreover, higher plant extracts have been considered as promising sources of novel antiTB leads [7]. This has prompted us to investigate selected Ethiopian medicinal plants, including Carissa edulis Vahl (Apocynaceae), Otostegia integrifolia Benth (Lamiaceae (Labiatae)), Persea Americana Mill (Lauraceae), Pterolobium stellatum (Forsk.) Brenan. (Fabaceae), and Vernonia amygdalina Del. (Asteraceae) for possible anti-TB activity. The plants have been traditionally used to treat respiratory or lung-related diseases, including $\mathrm{TB}$ for a very long time [8-11]. The present study attempted to screen the antmycobacterial activity of different solvent extract of these five Ethiopian medicinal plants, and Pterolobium stellatum was found to be the most promising plant for further investigation.

\section{Methods}

\section{Plant collection}

The roots of $O$. integrifolia, P. stellatum, and C. edulis were collected from an area near Angereb River, Gondar town, North West Ethiopia, about $730 \mathrm{~km}$ away from the capital, Addis Ababa. The root of $V$. amygdalina and the leaves of $P$. americana were collected from Bure town, North West Ethiopia, about $400 \mathrm{~km}$ far from Addis Ababa. The plants were authenticated by a taxonomist (Mr. Melaku Wondafrash) and a voucher specimen of each plant material was deposited at the National Herbarium, College of Natural and Computational Sciences, Addis Ababa University for future reference with voucher numbers Wk001, WK002, WK003, WK004 and WK005 for O. integrifolia, P. stellatum, C. edulis, $V$. amygdalina and $P$. americana, respectively. The plants were cleaned from dirt and soil and dried under shade for two weeks. The plants were spread out and regularly turned over to avoid fermenting and rotting. The dried root parts of plants were grinded using $0.75 \mathrm{~mm}$ sieve size hammer type mill, while the dried leaves were pulverized using a wooden mortar and pestle. The powdered material was weighed using an analytical balance and stored at room temperature.

\section{Experimental animals}

Swiss albino nulliparous and non-pregnant female mice weighing 31-36 g, and age 8-12 weeks were obtained from the Department of Pharmacology and Clinical Pharmacy, School of Pharmacy, Addis Ababa University. All animals were housed in an air-conditioned room and allowed to acclimatize for one week before commencement of the study. All the experiments were conducted in accordance with internationally accepted laboratory animal use, care and guideline [12] and the study was approved by the School of Pharmacy Ethics Committee (Protocol number was 042/12/pharmacy). Before and during the experiment, mice were allowed free access to standard pellets and water ad libitum.

\section{Bacterial strains and inoculums preparation}

Bacterial cells were $M$. tuberculosis H37Rv (ATCC no 27294, Manassas, VA) and three MDR-TB clinical isolate strains. The three MDR-TB clinical isolates were AOA8W-4, AOZ8W-4 and SO38SW-4. M. tuberculosis and MDR-TB strains were cultured and grown on Mycobacteria 7H11 medium following procedures described elsewhere [13]. The inoculum was then prepared by diluting cultures at $1 / 1000$ by adding $25 \mu \mathrm{l}$ cell culture to $25 \mathrm{ml}$ medium, $7 \mathrm{H} 9$ broth (4.7 g of Middlebrook $7 \mathrm{H} 9$ broth base [Difco - Becton Diskinson], $2 \mathrm{ml}$ of glycerol in $900 \mathrm{ml}$ water) enriched with ADC when cooled to $47^{\circ} \mathrm{C}$ [13].

\section{Extraction of plant materials Crude extract}

The air-dried, powdered roots of P. stellatum, O. integrifolia, C. edulis and V. amygdalina were exhaustively extracted with chloroform using maceration technique, while $P$. americana powdered leaves were extracted with acetone. Up on using chloroform and acetone solvents, maceration was carried out using one liter of the respective solvent for $72 \mathrm{~h}$, with regular shaking. The mixture was filtered with Whatman No. 42 filter paper and the filtrate was kept at $+4^{\circ} \mathrm{C}$. The marc was macerated again in the same solvent two times and filtered. The filtrates were combined evaporated under reduced pressure on a rotary evaporator (Buchi Rota Vapor R-200) and dried in oven at $40^{\circ} \mathrm{C}$ (Gallenkamp, England).

In parallel, the air-dried and powdered roots of $P$. stellatum, $O$. integrifolia and powdered leaves of $P$. americana were Soxhlet extracted with $80 \%$ methanol (4:1, methanol: water). The obtained extracts were filtered and evaporated under reduced pressure on a rotary evaporator and lyophilized. The extracts were kept refrigerated and away from light. Stock solutions of all extracts were prepared in DMSO at a concentration of $50 \mathrm{mg} / \mathrm{ml}$ and stored at $-20{ }^{\circ} \mathrm{C}$ until use. 


\section{Fractionation}

Antimycobacterial activity evaluation of the crude extract revealed $P$. stellatum chloroform root extract to have a better activity and further fractionation was pursued using this plant. The dried extract (8 g) was suspended in distilled water $(200 \mathrm{ml})$ and then successively partitioned with n-hexane and ethyl acetate in a separatory funnel. The n-hexane and ethyl acetate fractions were concentrated under reduced pressure using rotary evaporator (Buchi Rota Vapor R-200) and dried in an oven under $40{ }^{\circ} \mathrm{C}$, while the water fraction was dried using freeze drier.

\section{Acute oral toxicity test}

As no toxicity data was available for any part of $P$. stellatum chloroform extract, oral toxicity study was conducted using Organization for Economic Cooperation and Development (OECD) guidelines 423 [14]. Briefly, nine mice were randomly divided into three groups of three mice per cage. Before administration of single dose of the extract, the mice were fasted for $3 \mathrm{~h}$ and weighed. After administration of a single dose of extract, mice were fasted for $1 \mathrm{~h}$. The first group was given solvent (5\% DMSO in distilled water), while the second group were given $2 \mathrm{~g} / \mathrm{kg}$ (dissolved in 5\% DMSO) of the chloroform root extract of P. stellatum orally. The mice in the third group were provided with $P$. stellatum root extract $5 \mathrm{~g} / \mathrm{kg}$ dissolved in 5\% DMSO after following the first two groups for 14 days. The mice were observed continuously for $1 \mathrm{~h}$ after administration of the extract; intermittently for $4 \mathrm{~h}$, over a period of $24 \mathrm{~h}$, and then frequently for $24 \mathrm{~h}$ for 14 days. Gross behavioral changes such as loss of appetite, hair erection, lacrimation, tremors, convulsions, salivation, diarrhea, mortality and other signs of toxicity manifestation were observed.

\section{In vitro antimycobacterial assay \\ Colony count assay}

The antimycobacterial effect of the extracts was evaluated at concentrations ranging from $0.00244 \mathrm{mg} / \mathrm{ml}$ to $2.5 \mathrm{mg} / \mathrm{ml}$. The test concentrations of the extracts were selected based on cytotoxicity test results in previous studies $[4,10,15,16]$. Serial two-fold dilution of extracts was made in microtiter wells. Colony forming units (CFUs) were counted from triplicate dilutions and duplicate plates were used for each concentration of test extract and controls. The average CFUs were determined from three independent experiments. The percentage inhibition of growth was determined by dividing the CFUs of the test concentration by the CFUs of the negative control (solvent).

Each extract reconstituted with DMSO $(50 \mathrm{mg} / \mathrm{ml})$ was further diluted $(5 \mathrm{mg} / \mathrm{ml})$ with Middlebrook $7 \mathrm{H} 9$ broth supplemented with Middlebrook ADC. Activity was then measured and MIC was determined for the extracts as well as positive and negative controls following a method described elsewhere [13, 17]. The MIC was the concentration of extract at which $100 \%$ inhibition of mycobacterial growth was observed when compared with the growth control.

\section{Resazurin indicator assay}

M. tuberculosis H37Rv and clinical isolates of MDR-TB were cultured in Middlebrook $7 \mathrm{H} 9$ broth at $37{ }^{\circ} \mathrm{C}$ for two weeks in order to reach logarithmic phase growth. Test inoculums were prepared using a procedure described by Patricia and colleagues [18]. After incubation at $37^{\circ} \mathrm{C}$ for 7 days, $15 \mu \mathrm{l}$ of $0.01 \%$ resazurin solution in sterile water was added to the first growth control wells and incubated for $24 \mathrm{~h}$. Once the first sets of growth controls turned pink, the dye solution was added to the second set of growth controls and the test wells, incubated for $24 \mathrm{~h}$ at $37{ }^{\circ} \mathrm{C}$. Blue color in the wells containing the test compounds would indicate inhibition of growth, while pink indicates lack of inhibition of growth of $M$. tuberculosis [19]. MIC value was expressed as the lowest concentration of compound that caused $100 \%$ inhibition of mycobacterium growth [18]. All assays were run in triplicate and isoniazid was used as positive and DMSO as negative control.

\section{Statistical analysis}

Data are expressed as mean \pm standard error of mean as appropriate and Statistical analysis of all results was done using the Statistica 10 and GraphPad Prism 5 software. Analysis was done using one-way ANOVA followed by Duncan post hoc test. Level of statistical significance was set at $\alpha<0.05$.

\section{Results}

Information pertaining the preparation of the crude extracts is depicted in Table 1.

\section{Acute oral toxicity test}

Acute oral administration of the chloroform extract of $P$. stellatum at different doses showed no overt signs of distress for the 14-day observation period. Moreover, there were no observable symptoms of toxicity or deaths even at a dose of $5 \mathrm{~g} / \mathrm{kg}$. This indicates that the oral $\mathrm{LD}_{50}$ was greater than $5 \mathrm{~g} / \mathrm{kg}$. All treatment and control group mice gained weight and no significant changes in behavior was noted, suggesting that administration of the crude extract had negligible level of toxicity on growth of the animals. In addition, gross behavioral changes such as loss of appetite, hair erection, lacrimation, tremors, convulsions, salivation, diarrhea, mortality and other signs of toxicity manifestations were not observed. 
Table 1 Outcome of extraction in the preparation of crude extracts

\begin{tabular}{|c|c|c|c|c|c|c|}
\hline Plants & $\begin{array}{l}\text { Part (s) } \\
\text { used }\end{array}$ & Solvent & Extraction method & Raw material (g) & Yield g (\%) & Physical appearance \\
\hline \multirow[t]{2}{*}{ Otostegia integrifolia } & roots & chloroform & maceration & 300 & $2(0.67)$ & whitish powder \\
\hline & roots & $80 \%$ methanol & soxhlet & 200 & $1(0.5)$ & deep red gumy \\
\hline \multirow[t]{2}{*}{ Pterolobium stellatum } & roots & chloroform & maceration & 500 & $10(2)$ & brownish resin \\
\hline & roots & $80 \%$ methanol & soxhlet & 200 & $1.5(0.75)$ & deep red gumy \\
\hline \multirow[t]{2}{*}{ Persea americana } & Leaves & $80 \%$ methanol & soxhlet & 500 & $20(4)$ & Oily black \\
\hline & & Acetone & maceration & 300 & $3(1)$ & gumy black \\
\hline Carissa edulis & roots & chloroform & maceration & 300 & $2(0.67)$ & light green \\
\hline Vernonia amygdalina & roots & chloroform & maceration & 300 & $1.5(0.5)$ & black powder \\
\hline
\end{tabular}

\section{Antimycobacterial activity testing using CFU method}

Good growth of $M$. tuberculosis $\mathrm{H} 37 \mathrm{Rv}$ was evident in the microtiter plate wells containing only liquid Middlebrook 7H9 medium and in the universal Petri dishes containing solid Mycobacteria 7H11 medium, within three to four weeks. DMSO control at 2.5 to $0.0024 \%$, equivalent to solvent concentrations in test extracts, exhibited no inhibitory effect on mycobacterial growth as evidenced by higher CFU/ml (Table 2). Among the different concentrations of isoniazid used, total inhibition of growth of mycobacteria was observed at a concentration of $0.125 \mu \mathrm{g} / \mathrm{ml}$.

Extracts showed differential effects on the proliferation of Mycobacterium tuberculosis. The chloroform extract of $P$. stellatum appeared to be the most active as growth was totally inhibited at concentrations as low as $0.039 \mathrm{mg} / \mathrm{ml}$. Concentrations more than $0.3 \mathrm{mg} / \mathrm{ml}$ were required to bring about no growth with the $80 \%$ methanol extract of $P$. stellatum and O. integrifolia as well as with the chloroform extract of $O$. integrifolia. For the rest of the extracts, increasing concentrations $(>1 \mathrm{mg} / \mathrm{ml}$ ) were associated with growth arrest (Table 2).

The chloroform and $80 \%$ methanol extracts of $P$. stellatum and O. integrifolia as well as $80 \%$ methanol and acetone extracts of $P$. americana had significant antimycobacterial activity $(\alpha<0.001)$ against $M$. tuberculosis H37Rv compared to vehicle treated group. By contrast, $V$. amygdalina and $C$. edulis chloroform extracts did not have any detectable effect. It is interesting to note that although there was complete inhibition of growth of M. tuberculosis $\mathrm{H} 37 \mathrm{Rv}$ at concentrations greater than $1.25 \mathrm{mg} / \mathrm{ml}$ for $V$. amygdalina and $C$. edulis chloroform extracts, the difference failed to reach statistical significance (Table 2).

\section{Activity testing of crude extract on clinical isolates using Resazurin indicator method}

As the chloroform extract of $P$. stellatum demonstrated the highest activity $(\mathrm{MIC}=0.039 \mathrm{mg} / \mathrm{ml}$ ) against the standard strain in the CFU method, screening of the activity of this extract against clinical isolates of MDR-TB was carried out using resazurin indicator method. The resazurin assay results are depicted in Table 3. Color readings of the growth control wells were pink, demonstrating high levels of mycobacterial growth, while wells with broth alone appeared as blue color, which demonstrated no growth and lack of contamination. The isoniazid containing control wells were pink revealing the clinical isolates were isoniazid resistant. Whilst the extract demonstrated highest activity against AOZ8W-4 strain (MIC $78 \mu \mathrm{g} / \mathrm{ml}$ ), it had a moderate activity against both AOA8W-4 and SO38SW -4 strain (MIC $156 \mu \mathrm{g} / \mathrm{ml}$ ).

\section{Activity testing of solvent fractions on standard strains using Resazurin method}

As presented in Table 4, n-hexane and aqueous fractions were evaluated in a concentration series of 1000 to $0.977 \mu \mathrm{g} / \mathrm{ml}$, while ethyl acetate fraction with 200 to $0.195 \mu \mathrm{g} / \mathrm{ml}$ concentrations. The microtiter wells were pink below a concentration of $15.625 \mu \mathrm{g} / \mathrm{ml}$ for the $\mathrm{n}$-hexane fraction, indicating that this fraction was active against the standard strain $(\mathrm{MIC}=15.625 \mu \mathrm{g} / \mathrm{ml})$. By contrast, all wells were pink for the aqueous fraction, suggesting that this fraction was not active against the bacteria within the exposure concentrations used for the experiment. The ethyl acetate fraction was active against M. tuberculosis $\mathrm{H} 37 \mathrm{Rv}(\mathrm{MIC}=0.195 \mu \mathrm{g} / \mathrm{ml})$, indicating that this fraction is the most active fraction of $P$. stellatum chloroform extract (Table 5). As described above, all wells treated with the vehicle were pink, demonstrating no inhibitory role of the vehicle.

\section{Discussion}

Current TB therapy consists of treatment with a combination of drugs. This combination therapy causes hepatotoxicity as the major side effect as well as development of drug resistance. To avert toxicity and reduce ineffectiveness of current anti-TB drugs, medicinal plants are considered as potential anti-tuberculosis agents that can be used in combination with the standard anti- 


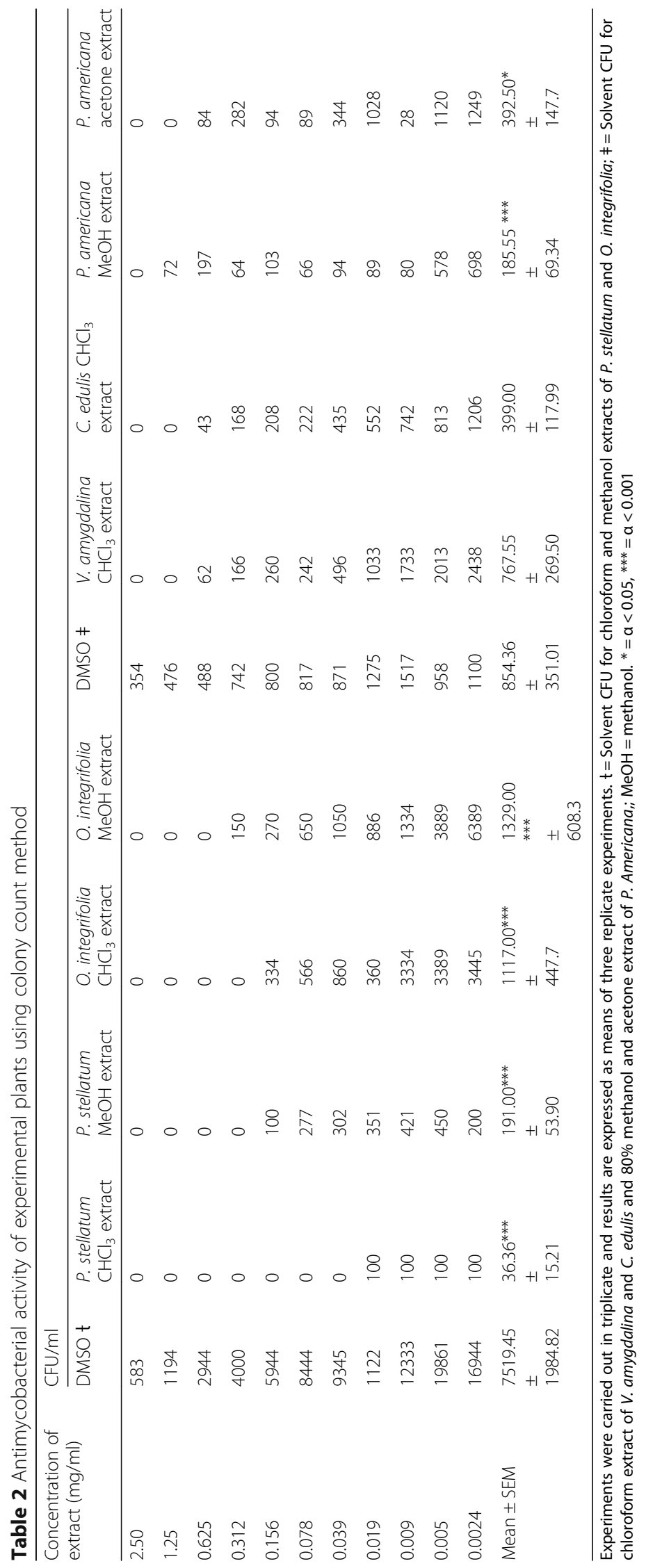


Table 3 Antimycobacterial activity test of Pterolobium stellatum chloroform extract against MDR-TB clinical isolates

\begin{tabular}{|c|c|c|c|c|}
\hline \multirow[b]{2}{*}{$\begin{array}{l}\text { Plant extracts } \\
\text { and controls }\end{array}$} & \multirow[b]{2}{*}{$\begin{array}{l}\text { Concentration } \\
(\mathrm{mg} / \mathrm{ml} \text { or } \%)\end{array}$} & \multicolumn{3}{|c|}{$\begin{array}{l}\text { MDR-TB clinical isolates' suspension } \\
\text { color }\end{array}$} \\
\hline & & AOA8W-4 & AOZ8W-4 & SO38SW-4 \\
\hline \multirow{11}{*}{$\begin{array}{l}\text { P. stellatum } \\
\mathrm{CHCl}_{3} \text { extract }\end{array}$} & 2.500 & blue & blue & blue \\
\hline & 1.250 & blue & blue & blue \\
\hline & 0.625 & blue & blue & blue \\
\hline & 0.312 & blue & blue & blue \\
\hline & 0.156 & blue & blue & blue \\
\hline & 0.078 & pink & blue & pink \\
\hline & 0.039 & pink & pink & pink \\
\hline & 0.019 & pink & pink & pink \\
\hline & 0.009 & pink & pink & pink \\
\hline & 0.005 & pink & pink & pink \\
\hline & 0.0024 & pink & pink & pink \\
\hline DMSO control & $2.5-0.0024 \%$ & Pink & Pink & Pink \\
\hline \multirow[t]{6}{*}{ Isoniazid } & $1 \times 10^{-3}$ & Pink & Pink & Pink \\
\hline & $0.5 \times 10^{-3}$ & Pink & Pink & Pink \\
\hline & $0.25 \times 10^{-3}$ & Pink & Pink & Pink \\
\hline & $0.125 \times 10^{-3}$ & Pink & Pink & Pink \\
\hline & $0.06 \times 10^{-3}$ & Pink & Pink & Pink \\
\hline & $0.03 \times 10^{-3}$ & Pink & Pink & Pink \\
\hline Growth control & - & Pink & Pink & Pink \\
\hline Sterility control & - & blue & blue & blue \\
\hline
\end{tabular}

Experiments were carried out in triplicate and results are expressed as means of three replicate experiments. - = Not applicable tuberculosis drugs or alone [20]. In this study, antimycobacterial activity of crude extract of $O$. integrifolia, $V$. amygdalina, $C$. edulis, $P$. americana, $P$. stellatum and as well as fractions of the most active crude extract was investigated.

From the aerial parts of $O$. integrifolia otostegin A, otostegin B, 15-epi-otostegin B, preleoheterin, leoheterin, and related compounds, including leopersin C, 15-epi-leopersin $\mathrm{C}$, ballonigrin, vulgarol, and 8-O-acetylharpagide were isolated and reported. In addition, the essential oil and chloroform extract of air-dried leaves of O. integrifolia constitute monoterpenes, sesquiterpenes, diterpenes and their derivatives were identified [21]. Phytochemical screening study report indicated that saponins, glycosides and tannins, which are known to be bioactive purgative principles were present in $V$. amygdalina extract. Flavonoids are also present in the plant that possess antioxidant activity and may play a beneficial role in cancer prevention and offer some protection against diabetes and atherosclerosis [22].

The chemical compositions of C. edulis have extensively been reported. Roots contain an active ingredient, carissin that may prove useful in the treatment of cancer. The twigs contain quebrachytol and cardioglycosides that are useful as an anthelmintic against tapeworm [23] and the roots contain lupeol (has antiviral activity), oleuropein, carissol and $\beta$-amyrin [24]. Major chemical constituents of $P$. americana include the following: the leaf contains volatile oil, flavonoids and coumarins; the fruit contains sesquiterpenes and carbohydrates; the seed contains fixed oil consisting of vitamins $\mathrm{A}, \mathrm{D}_{3}$, alpha tocopherol and cholesterol. The fruit is a significant source of protein, monounsaturated fatty acids, vitamin A, thiamin, riboflavin, niacin, vitamin $B 6$, vitamin $C$, vitamin $E$, folate, vitamin $\mathrm{K}$, pantothenic acid, magnesium, manganese, phosphorus and the amino acids tryptophan, valine,

Table 4 Test suspension colors obtained from fractions tested against Mycobacterium tuberculosis H37Rv

\begin{tabular}{|c|c|c|c|c|c|c|c|c|c|}
\hline \multicolumn{2}{|l|}{$\mathrm{n}$-hexane } & \multicolumn{2}{|l|}{ Ethyl Acetate } & \multicolumn{2}{|l|}{ Aqueous } & \multicolumn{2}{|l|}{ Isoniazid } & \multicolumn{2}{|l|}{ DMSO } \\
\hline Conc $(\mu \mathrm{g} / \mathrm{ml})$ & Color & Conc $(\mu \mathrm{g} / \mathrm{ml})$ & Color & Conc $(\mu \mathrm{g} / \mathrm{ml})$ & Color & Conc $(\mu \mathrm{g} / \mathrm{ml})$ & Color & Conc (\%) & Color \\
\hline 1000 & blue & 200 & blue & 1000 & pink & 1 & blue & 2.5 & pink \\
\hline 500 & blue & 100 & blue & 500 & pink & 0.5 & blue & 1.25 & pink \\
\hline 250 & blue & 50 & blue & 250 & pink & 0.25 & blue & 0.625 & pink \\
\hline 125 & blue & 25 & blue & 125 & pink & 0.125 & blue & 0.312 & pink \\
\hline 62.5 & blue & 12.5 & blue & 62.5 & pink & 0.06 & pink & 0.156 & pink \\
\hline 31.25 & blue & 6.25 & blue & 31.25 & pink & 0.03 & pink & 0.078 & pink \\
\hline 15.625 & blue & 3.125 & blue & 15.625 & pink & - & - & 0.039 & pink \\
\hline 7.813 & pink & 1.563 & blue & 7.813 & pink & - & - & 0.02 & pink \\
\hline 3.906 & pink & 0.781 & blue & 3.906 & pink & - & - & 0.01 & pink \\
\hline 1.953 & pink & 0.391 & blue & 1.953 & pink & - & - & 0.005 & pink \\
\hline 0.977 & pink & 0.195 & blue & 0.977 & pink & - & - & 0.0024 & pink \\
\hline
\end{tabular}

Experiments were carried out in triplicate and results are expressed as means of three replicate experiments. - = Not applicable 
Table 5 Minimum inhibitory concentrations of solvent fractions against Mycobacterium tuberculosis H37Rv

\begin{tabular}{ll}
\hline Solvent fraction & $\begin{array}{l}\text { Minimum Inhibitory Concentration } \\
(\mu \mathrm{g} / \mathrm{ml})\end{array}$ \\
\hline n-hexane fraction & 15.625 \\
Ethyl acetate fraction & 0.195 \\
Aqueous fraction & +++ \\
Isoniazid & 0.125 \\
Growth control & +++ \\
DMSO control & +++ \\
\hline
\end{tabular}

$+++=$ Growth

tyrosine, threonine, phenylalanine and methionine [25]. Chemical classes present in P. stellatum $80 \%$ root extract are terpenoids, saponins and tannins and had antibacterial activity as reported by previous study.

The result of the study revealed that three of the experimental plants had significant anti-tuberculosis activity. The activity was seen with chloroform and methanol extracts of $P$. stellatum and $O$. integrifolia as well as with methanol and acetone extracts of $P$. americana. In addition, fractions from the most active plant, P. stellatum had demonstrated promising antimycobacterial activity [8].

MICs of all experimental plant extracts and solvent fractions of the most active plant extract were determined by CFU method and microplate resazurin assay method. As evidenced from Tables 2 and 3, P. stellatum chloroform extract was endowed with lower MIC by CFU method than by microplate resazurin assay method, although test organisms were different. It has been reported that the MIC exhibited by a compound/extract depends on the technique used for determination. MICs obtained in a liquid medium are lower than that obtained from a solid medium, as the drug has to diffuse through the matrix in the solid medium in order to exert activity [20].

MIC of P. stellatum chloroform extract was evaluated using CFU and Resazurin indicator method. The finding in the later method revealed that the MICs were 0.078, 0.156 and $0.156 \mathrm{mg} / \mathrm{ml}$ against AOZ8W-4, AOA8W-4 and SO38SW-4 MDR-TB clinical isolates, respectively. However, the extract had lower MIC $(0.039 \mathrm{mg} / \mathrm{ml})$ against the standard strain. The difference in MICs might be ascribed to the difference in susceptibility of the standard strain and MDR-TB clinical isolates towards the extract. Furthermore, this apparent difference might be attributed to more favorable growth conditions provided by agar culture medium to extract-treated bacilli in colony count method or the drug susceptible standard strain and the drug resistant strain might have different growth conditions. Another cause for the different MICs of P. stellatum chloroform extract could be the slight difference in sensitivities of colony count method and resazurin indicator method as reported by Taneja and Tyagi [26]. According to this study, Resazurin indicator assay was noted to be superior to the colony count assay in that it distinguished between metabolically active dormant bacteria and non-viable organisms, unlike the colony count assay that could not differentiate between these two populations.

In this study, $P$. stellatum chloroform extract showed promising activity against $M$. tuberculosis $\mathrm{H} 37 \mathrm{Rv}$ and AOZ8W-4, with complete inhibition at $0.039 \mathrm{mg} / \mathrm{ml}$ and $0.078 \mathrm{mg} / \mathrm{ml}$, respectively. These values are within the range stated by the Clinical and Laboratory Standards Institute [27]. In addition, the MDR-TB clinical isolates were resistant to isoniazid, while this plant was active against the clinical isolates of MDR-TB, possibly suggesting that the plant could have an obvious advantage over the standard drug. Moreover, the activity displayed by this extract makes the plant to be a promising plant according to Tosun et al. [28], which states that compounds with an MIC of less than $10 \mu \mathrm{g} / \mathrm{ml}$, and ideally less than $2 \mu \mathrm{g} / \mathrm{ml}$ could have a potential for further investigation.

There is sparse data in the literature about the antimycobacterial activity of $P$. stellatum, making comparison a bit difficult. A study reported that $80 \%$ ethanol leaf extract of the plant had shown activity $(\mathrm{MIC}=250 \mathrm{mg} / \mathrm{ml}$ ) on $M$. tuberculosis H37Rv [9]. This value is much higher than the value obtained in this study, possibly indicating that non-polar constituents might be more responsible for the observed antitubercular activity. Efforts made to compare activity of the chloroform extract of $P$. stellatum with other plants showed either better or comparable activity. Activity was better compared to stem bark extract of Anogeissus leiocarpus [13] and comparable to that of the chloroform leaf extract of Byrsonima fagifolia [29].

Although $80 \%$ methanol extract of $P$. stellatum $(\mathrm{MIC}=$ $0.312 \mathrm{mg} / \mathrm{ml}$ ), P. americana $(\mathrm{MIC}=2.5 \mathrm{mg} / \mathrm{ml}$ ) and $O$. integrifolia $(\mathrm{MIC}=0.312 \mathrm{mg} / \mathrm{ml}$ ) as well as chloroform extract of O. integrifolia $(\mathrm{MIC}=0.312 \mathrm{mg} / \mathrm{ml}$ ) and acetone extract of $P$. americana $(\mathrm{MIC}=1.25 \mathrm{mg} / \mathrm{ml})$ had significantly higher activity than vehicle-treated controls, they failed to exhibit promising activity according to Tosun [30] or Sánchez [31]. The MICs in this finding are lower/equal than a study done on methanol extract of Pelargonium sidoides $(\mathrm{MIC}=5000 \mu \mathrm{g} / \mathrm{ml}$ ) as well as methanol extract of Capparis brassi, Entada africana and Combretum species (MIC $=1250 \mu \mathrm{g} / \mathrm{ml}$ each) against M. tuberculosis $\mathrm{H} 37 \mathrm{Rv}$ [12]. However, the MICs were higher than that of chloroform extract of Byrsonima fagifolia (MIC $=62.5 \mu \mathrm{g} / \mathrm{ml}$ ) [29]. This difference might be imputed to the fact that different plant species may contain different active constituents at varying amount and/or different in vitro methods were used. 
Previous studies reported several plants with promising anti-tubercular activity [13, 29-33]. Studies had mostly reported activity in the plant families of Asteraceae, Lamiaceae, Fabaceae and Apiaceae, among others [34]. It is noticeable from the present study that plants exhibiting activity belong to Fabaceae, Lamiaceae and Lauraceae families, which is in agreement with the plant families previously reported [34].

Antimycobacterial activity evaluation revealed that $P$. stellatum chloroform root extract to have a better activity and further fractionation was pursued and activity of the fractions was evaluated. Accordingly, the ethyl acetate fraction was found to be the most active fraction, based on MIC values $(0.195 \mu \mathrm{g} / \mathrm{ml})$, which indicated that antimycobacterial constituents were contained in this fraction. Further work is underway to isolate and characterize active principles from this fraction.

\section{Conclusion}

The results of this study showed that $P$. stellatum, $O$. integrifolia and $P$. americana are endowed with a significant antimycobacterial activity. However, it seems that the potential to develop new compounds against both drug susceptible as well as MDR-TB rests with $P$. stellatum. The ethyl acetate fraction of this plant was the most active solvent fraction and further study is underway with this fraction. Although the present study provided evidence for the traditional use of some of the plants for treatment of $\mathrm{TB}$, the evidence did not support the use of V. amygdalina and C. edulis for the same.

\section{Abbreviations}

ADC: Albumin dextrose complex; AIDS: Acquired immune deficiency syndrome; ANOVA: Analysis of variance; CFU: Colony forming unit; DMSO: Dimethyl sulphoxide; HIV: Human immunodeficiency virus; MDR-TB: Multidrug resistant tuberculosis; MIC: Minimum inhibitory concentration; TB: Tuberculosis; WHO: World Health Organization; XDR-TB: Extremely drug resistant tuberculosis

\section{Acknowledgements}

The authors are thankful to Addis Ababa University, University of Gondar and Armauer Hanson Research Institute for funding the study.

\section{Funding}

The sources of funding for this research are as follows:

The source of fund for the design of the study and plant sample collection was Addis Ababa University where as Armauer Hanson Research Institute provided lab space and consumables. Analysis and interpretation of data and manuscript writing was funded by University of Gondar.

\section{Availability of data and materials}

Almost all the materials and data of our study are included in the manuscript. A few of the material and data will be available to other researchers upon request.

\section{Authors' contributions}

All authors have made substantial contributions in the research, preparation and revision of manuscript. The principal contributor for the conception and design, acquisition, analysis and interpretation of data as well as manuscript writing was Wubayehu Kahaliw (Ph. D). Ephrem Engdawork (Ph. D) and Abreham Aseffa (Ph. D) involved in the design of the study, revising the manuscript critically for important intellectual content. Markos Abebe (Ph. D) and Mekonnen Teferi (DVM, Msc) contributed in data acquisition and in revising manuscript. Each author has participated in the work and has given final approval of the version to be published.

\section{Competing interests}

The authors declare that they have no competing interests.

Consent for publication

Not applicable.

Ethics approval and consent to participate

All the experiments were conducted in accordance with internationally accepted laboratory animal use, care and guideline and the study was approved by the School of Pharmacy Ethics Committee (Protocol number was 042/12/pharmacy). Before and during the experiment, mice were allowed free access to standard pellets and water ad libitum.

\section{Author details}

${ }^{1}$ Department of Pharmacology, School of Pharmacy, College of Medicine and Health Sciences, University of Gondar, P. O. Box: 196, Gondar, Ethiopia.

${ }^{2}$ Armauer Hanson Research Institute, P. O. Box: 1005, Addis Ababa, Ethiopia. ${ }^{3}$ Department of Pharmacology and Clinical Pharmacy, School of Pharmacy, College of Health Sciences, Addis Ababa University, P. O. Box: 1176, Addis

Ababa, Ethiopia.

Received: 9 October 2016 Accepted: 6 January 2017

Published online: 08 March 2017

\section{References}

1. Brudey K, Driscoll JR, Rigouts L. Mycobacterium Tuberculosis complex genetic diversity: mining the fourth international spoligotyping database (SpolDB4) for classification. BMC Microbiol. 2006;6:23

2. WHO. World TB report 2001. Global tuberculosis control: surveillance, planning, financing. Geneva: World Health Organization; 2002.

3. WHO. Global tuberculosis report 2014. Geneva: World Health Organization; 2015.

4. Mariita RM, Okemo PO, Orodho JA, Kirimuhuzya C, Otieno JN, Magadula JJ. Efficacy of 13 medicinal plants used by indigenous communities around Lake Victoria, Kenya, against tuberculosis, diarrhoea causing bacteria and Candida Albicans. IJPT. 2010;2(3):771-91.

5. Raiz M, Zia-Ul Haq M, Saad B. Anthocyanins and human health: Biomolecular and Therapeutic Aspects. Switzerland: Springer International Publishing AG; 2016

6. Hamisi MM, Vitus AN, Andrew M. Anti-TB Natural Products in Tanzanian Medicinal Plants. 2009. http://www.nimr.or.tz/ Anti-TB Natural Products in Tanzanian Medicinal Plants. Accessed 31 Oct 2015

7. Mitscher LA, Baker WR. A search for novel chemotherapy against tuberculosis amongst natural products. Pure Appl Chem. 1998;70(2):365-271.

8. Andualem G, Umar S, Getnet F, Tekewe A, Alemayehu H, Kebede N. Antimicrobial and phytochemical screening of methanol extracts of three medicinal plants in Ethiopia. Adv Biol Res. 2014;8(3):101-6.

9. Balcha E, Mengiste B, Gebrelibanos M, Worku I, Ameni G. Evaluation of Invitro Anti-mycobacterial Activity of Selected Medicinal Plants in Mekelle, Ethiopia. World Appl Sci J. 2014;31(6):1217-20.

10. Endale A, Bisrat D, Animut A, Bucar F, Asres K. In vivo antimalarial activity of a Labdane Diterpenoid from the leaves of Otostegia integrifolia benth. Phytother Res. 2013. doi:10.1002/ptr.4948.

11. Getahun A. Some Common Medicinal and Poisonous Plants Used in Ethiopian Folk Medicine. 1976. http://www.mrc.ac.za/. Accessed 14 Dec 2014.

12. Institute for Laboratory Animal Research (ILAR). Guide for the care and use of laboratory animals. Washington: National Academy Press; 2001.

13. Mann A, Amupitan JO, Oyewale AO, Okogun JI, Ibrahim K, Oladosu P, Lawson L, Olajide I, Nnamdi A. Evaluation of in vitro antimycobacterial activity of Nigerian plants used for treatment of respiratory diseases. Afr J Biotechnol. 2008:7(11):1630-6.

14. OECD guideline for testing of chemicals. Acute Oral Toxicity- Acute Toxic Class Method. 2001

15. Gomez-Flores R, Arzate-Quintana C, Quintanilla-Licea R, Tamez-Guerra P, Tamez-Guerra R, Monreal-Cuevas E, Rodríguez-Padilla C. Antimicrobial Activity of Persea americana Mill (Lauraceae) and Gymnosperma glutinosum 
(Spreng.) (Asteraceae) leaf extracts and active fractions against Mycobacterium tuberculosis. Am-Euras J Sci Res. 2008;3(2):188-94.

16. Nvau JB, Oladosu PO, Orishadipe AT. Antimycobacterial evaluation of some medicinal plants used in Plateau State of Nigeria for the Treatment of Tuberculosis. Agric Biol J N Am. 2011;2(9):1270-2.

17. Xuan L, David P, Jose AA, Begona G, Silva M, Aida D, Elsa A, Maria-Jose UF. Antimycobacterial evaluation and preliminary phytochemical investigation of selected medicinal plants traditionally used in Mozambique. J Ethnopharmacol. 2011;137:114-20

18. Patricia CE, Juan MJ, Elvira G, Noemí W, María Y, Maríadel R. Antimycobacterial activity of constituents from Foeniculum Vulgare Var. Dulce Grown in Mexico. Molecules. 2012;17:8471-82.

19. Deepthi R, Junise V, Shibin SS, Rajesh S. Isolation, identification and Antimycobacterial evaluation of Piperine from Piper longu. Pharm Lett. 2012:4(3):863-8

20. Nair SS, Pharande RR, Bannalikar AS, Mukne AP. In vitro anti-mycobacterial activity of acetone extract of glycyrrhiza glabra. J Pharm Pharmacogn Res. 2015;3(4):81.

21. Tesso H, König A. Terpenes from Otostegia integrifolia. Phytochemistry. 2004;65:2057-62.

22. Yusuf $A B$, Umar IA, Nok AJ. Effects of methanol extract of vernonia amygdalina leaf on survival and some biochemical parameters in acute trypanosoma brucei infection. Afr J Biochem Res. 2012;6(12):150-8.

23. Orwa C, Mutua A, Kindt R, Jamnadass R, Simons A. Agroforestree Database: a Tree Reference and Selection Guide Version 4.0. 2009. http.//www.kemri.org/. Accessed 29 Oct 2015

24. Tolo MF, Rukung WG, Muli WF, Ochora MJ, Irungu NB, Muthaura NC, Wanjiku KC, Mungai MG, Quang N, Hashimoto K, Asakawa Y. The antiviral activity of compounds isolated from Kenyan Carissa edulis (Forssk.) vahl. JMPR. 2010;4(15):1517-22.

25. Yukes JE, Balick MJ, editors. Dominican medicinal plants: a guide for health care providers. 2nd ed. New York: The New York Botanical Garden; 2010

26 Taneja NK, Tyagi JS. Resazurin reduction assays for screening of antitubercular compounds against dormant and actively growing Mycobacterium tuberculosis, Mycobacterium bovis BCG and Mycobacterium smegmatis. J Antimicrob Chemother. 2007;60:288-93.

27 CLSI. Performance standards for antimicrobial susceptibility testing: twentyfourth informational supplement. CLSI document M100-524. Wayne: Clinical and laboratory standards institute; 2014

28 Tosun F, Akyüz Kizilay C, Sener B, Vural M, Palittapongarnpim P. Antimycobacterial screening of some Turkish plants. J Ethnopharmacol. 2004;95:273-5.

29 Higuchi CT, Pavan FR, Sato DN. Apolar compounds with antitubercular activity. Compl Alt Med. 2008;1:5.

30 Sánchez JG, Kouznetsov W. Anti-mycobacterial susceptibility testing methods for natural products research. Braz J Microbiol. 2010:41:270-7.

31 Billo M, Cabalion P, Waikredre J, Fourneau C, Bouttier S, Hocquemiller R, Fournet A. Screening of some New Caledonian and Vanuatu medicinal plants for anti-mycobacterial activity. J Ethnopharmacol. 2005;96(3):569-75.

32 Jiménez-Arellanes $\mathrm{A}$, Meckes $\mathrm{M}$, Torres J, Luna-Herrera J. Antimycobacterial Triterpenoids from Lantana hispida (Verbenaceae). J Ethnopharmacol. 2007;111:202-5.

33 Newton SM, Lau C, Gurcha SS, Besra GS, Wright CW. The evaluation of fortythree plant species for In vitro Antimycobacterial activities; isolation of active constituents from Psoralea corylifolia and Sanguinaria canadensis. J Ethnopharmacol. 2002;79:57-67.

34 Gautam R, Saklani A, Jachak SM. Indian medicinal plants as a source of Antimycobacterial agents. J Ethnopharmacol. 2007;110:200-34.

\section{Submit your next manuscript to BioMed Central and we will help you at every step:}

- We accept pre-submission inquiries

- Our selector tool helps you to find the most relevant journal

- We provide round the clock customer support

- Convenient online submission

- Thorough peer review

- Inclusion in PubMed and all major indexing services

- Maximum visibility for your research

Submit your manuscript at www.biomedcentral.com/submit

CBiomed Central 